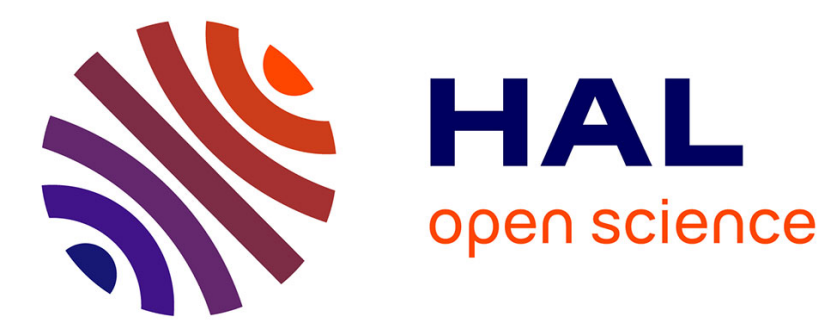

\title{
Robust, Affordable, Semi-Direct Mars Mission Jean-Marc Salotti
}

\section{To cite this version:}

Jean-Marc Salotti. Robust, Affordable, Semi-Direct Mars Mission. Acta Astronautica, 2016, 127, pp.235-248. hal-01670415

\section{HAL Id: hal-01670415 \\ https://hal.science/hal-01670415}

Submitted on 21 Dec 2017

HAL is a multi-disciplinary open access archive for the deposit and dissemination of scientific research documents, whether they are published or not. The documents may come from teaching and research institutions in France or abroad, or from public or private research centers.
L'archive ouverte pluridisciplinaire HAL, est destinée au dépôt et à la diffusion de documents scientifiques de niveau recherche, publiés ou non, émanant des établissements d'enseignement et de recherche français ou étrangers, des laboratoires publics ou privés. 


\title{
Robust, Affordable, Semi-Direct Mars Mission
}

\author{
Jean-Marc Salotti \\ Intégration du Matériau au Système laboratory, CNRS, Bordeaux INP, France. \\ Association Planète Mars, France. \\ Jean-marc.salotti@ensc.fr
}

\begin{abstract}
A new architecture is proposed for the first manned Mars mission, based on current NASA developments (SLS and Orion), chemical propulsion for interplanetary transit, aerocapture for all vehicles, a split strategy, and a long stay on the surface. Two important choices make this architecture affordable and appropriate for the first mission. The first is splitting the Earth return vehicle into two parts that are launched separately and dock in Mars orbit. This is necessary to make aerocapture feasible and efficient, which considerably reduces mass. The second is reducing the crew to 3 astronauts. This simplifies the mission and reduces the SLS payload mass under the 45-metric ton limit for a direct TMI (trans-Mars injection) burn without LEO assembly. Only 4 SLS launches are required. The first takes the Mars ascent vehicle and in situ resource utilization systems to the planet's surface. The second takes the first part of the Earth return vehicle, the habitat, into Mars orbit. Two years later, two further SLS launches take a dual-use habitat (outbound trip and surface), Orion, and an enhanced service module to LEO, and then into Mars orbit, followed by the landing of the habitat on the surface. Transit time is demonstrated to be easily reduced to less than 6 months, with relatively low impact on propellant mass and none at all on the architecture.
\end{abstract}

Keywords: Manned Mars mission, semi-direct Mars mission

\author{
Abbreviations: \\ EDL: Entry, Descent and Landing \\ ERV: Earth Return Vehicle \\ HIAD: Hypersonic Inflatable Atmospheric Decelerator \\ IMLEO: Initial Mass in Low Earth Orbit \\ ISRU: In Situ Resource Utilization \\ LEO: Low Earth Orbit \\ MAV: Mars Ascent Vehicle \\ MSR: Mars Sample Return \\ RCS: Reaction Control System \\ SIAD: Supersonic Inflatable Atmospheric Decelerator \\ SLS: Space Launch System (NASA rocket) \\ TEI: Trans-Earth Injection \\ TMI: Trans-Mars Injection
}




\section{Introduction}

Numerous architectures have already been proposed for manned Mars missions [1-15]. Some authors recommend that chemical propulsion should be abandoned, as it makes a manned mission to the red planet overly complex and risky. In 2009, NASA conducted an extensive, detailed study [3]. Chemical propulsion systems were studied and their impact on the mission was so negative in terms of IMLEO (Initial Mass in low Earth orbit) and the number of heavy launches that the obvious conclusion was to reject this option. Interestingly, a recent IAA (International Academy of Astronautics) summary of previous work on manned missions to Mars did not present a consensus on the choice of propulsion system for the first interplanetary flights and chemical propulsion was still considered a possible option [16]. This paper is not intended to summarize and comment on the various arguments, which were probably all technically founded, but to address the following important question: Why do some experts still believe that chemical propulsion is competitive? Did NASA investigate every possible option before concluding that chemical propulsion would lead to an overly complex mission or is there a way of mitigating that complexity, without compromising on robustness and risk? In order to address that problem in the context of current space exploration programs, the following assumptions were made:

- The objective is to land on the surface of Mars and return to Earth.

- NASA SLS will be the launcher. According to NASA, the SLS payload capability will be 130 metric tons for LEO and it will be around 45 metric tons for trans-Mars injection using chemical propulsion systems [17].

- As the objective is to propose a realistic, affordable mission, it is necessary to comply with the constraints specified by NASA for SLS launches, with a maximum of two per year.

- The duration of the outbound trip shall be less than 6 months in the worst planet configuration (Mars at aphelion). This constraint is assumed to ensure that the scenario is robust and competitive, as well as reduce radiation exposure.

- An Orion capsule shall be used for the crew launch and return to Earth. This constraint was also assumed in the NASA reference missions $[4,5]$.

- Whenever possible, only data based on solid technical studies shall be used for mass estimates.

One important objective was not only to use chemical propulsion systems, but also to design a simple, affordable mission. Several studies suggested paying particular attention to the feasibility of aerocapture, a key option for reducing IMLEO and to the complexity of EDL (entry, descent, and landing) systems $[12,14,18,19]$. This complexity is indeed closely-related to that of the preparatory missions and, therefore, the total costs [20,21]. Finally, it is also important to look at a possible roadmap, providing acceptable risks for the first manned missions and addressing the issue of the long-term viability of the Mars exploration program: the first manned mission should not be the last.

This study is split into 3 parts. Section 2 reviews the main elements to be developed for the mission and addresses aerocapture and EDL issues, as well as presenting the mission architecture. As all modules are to be sent by means of direct trans-Mars injection burns without LEO assembly, one important issue is to ensure that the mass of each payload remains below the 45 -metric ton limit. This problem is addressed for each SLS payload in sections 3 to 5 . Section 7 discusses backup and roadmap issues. 


\section{Methodology}

\subsection{Main elements of the mission}

In addition to a heavy launcher, a manned mission to Mars requires the development of several important elements:

1) A space habitat for the interplanetary flight.

2) A surface habitat.

3) A Mars ascent vehicle to return from the surface to Mars orbit.

4) A propulsion system to return the manned vehicle to Earth.

5) A small capsule, used for the launch from Earth, as well as reentry into the Earth's atmosphere and landing on the last day of the mission.

6) In addition to these modules, several huge heat shields are required for entry into the Martian atmosphere.

Figure 1 shows drawings of these 6 elements.


Figure 1: Drawings of the 6 major elements to be sent to Mars (Credit NASA).

There are a number of ways to send these elements to Mars. It is generally assumed that some elements, typically the Mars ascent vehicle, may be sent in advance, according to a split strategy [4]. This is more difficult for some other elements. For instance, the wet propulsion system (tanks filled with propellant to be used only for the return) is usually considered an essential part of the return vehicle, which also includes the space habitat, thus making it more practical to send these elements together with the capsule in a single vehicle. As the sum of these elements would undoubtedly exceed the launcher capability (at least 60 tonnes, according to our calculations), it would require the assembly of a giant vehicle in LEO. As in numerous Mars mission architectures, this choice was made by NASA in the 2009 study for both the nuclear thermal and chemical options [4]. This had major consequences: as the vehicle was huge, with several modules attached at different locations, it was felt that an aerocapture maneuver would be very complex, risky, and inefficient. The NASA report therefore recommended abandoning the idea of aerocapture for the manned vehicle, with two main consequences. First, it entailed a significant mass penalty to bring the propellant for Mars orbit insertion, second, an increase in the size and mass of the interplanetary vehicle, and, third, an increase in the complexity and duration of the assembly phase. This necessitated multiple SLS missions, including some exclusively to bring boosters to LEO to maintain the operational modules in an acceptable parking orbit. In other words, it is very important to examine all options for sending these elements to Mars. If, for instance, aerocapture is 
possible, at the expense of major constraints on the design of these elements or the mission architecture itself, it may be preferable to accept these constraints to ensure the affordability of the mission.

Another significant challenge concerns the development of entry, descent, and landing systems for heavy vehicles. Several studies recommended making the choice of the EDL systems a major parameter of the trade tree $[10,19]$. Aerocapture and EDL issues are discussed in the next sections.

\subsection{Aerocapture}

Aerocapture is a key option for reducing the mass of the interplanetary vehicle $[4,18,22,23]$. As the $\Delta V$ is in general greater than $2 \mathrm{~km} / \mathrm{s}$, a propulsive Mars orbit insertion would require a heavy propulsion system, representing over $60 \%$ of the arrival mass. Aerocapture also requires a heavy heat shield. Its mass depends on the velocity, shape, and ballistic coefficient of the vehicle, generally representing less than $30 \%$ of the arrival mass $[5,22]$. Moreover, a landing vehicle may be equipped with a dual-use heat shield (aerocapture and descent), providing that a margin is built in for the heat load and deceleration peak. The additional mass in this case could represent less than $10 \%$ of the arrival mass.

Instead of defining the elements of the interplanetary vehicle first and determining how to implement aerocapture, this approach started by considering the constraints and issues of aerocapture and tried to find the best vehicle configuration to overcome these issues.

The objective of an aerocapture maneuver is to use the atmosphere of the planet to slow the vehicle down for orbit insertion. If braking is insufficient, the vehicle follows a hyperbolic trajectory and escapes the planet's gravitational field. If it is too hard and exceeds the peak deceleration limit (generally 5 Earth g [18]), the astronauts may be killed and, if they survive, they have to handle an emergency landing. For Mars orbit insertion, the aerocapture maneuver requires the use of accurate GNC systems, in order to enter and follow a narrow corridor in the upper layers of the Martian atmosphere and exit it at the right time and place. The width of the corridor and the complexity of the maneuver depend on several parameters, such as the initial velocity, angle of attack, model and current state of the atmosphere, ballistic coefficient, lifting variability, efficiency of thermal protection, accuracy of GNC systems, etc. $[4,18]$. Among these parameters, the ballistic coefficient plays an important role. If it is very high with poor lifting capabilities, the trajectory cannot be adequately controlled. For vehicles with the same shape and density, the ballistic coefficient grows faster than lift with the size of the vehicle. In other words, it is easier to perform aerocapture with relatively small, light vehicles. Massive vehicles require much greater lifting capabilities. This is possible using larger heat shields, but at the expense of the heat load, structural mass, and complexity of GNC systems. In addition, if the shape of the vehicle is not simple and symmetrical, shielding is more difficult and guidance is even more complex. Last but not least, there is an issue with testing and qualifying aerocapture for large, massive vehicles that need to be assembled in LEO before interplanetary flight [20]. As the qualification of any space device cannot be completed without a final test at scale one under the same conditions as those expected for the manned flight, even a single test would require an extremely expensive, complex mission. Moreover, as the variability of the aerocapture maneuver is relatively high (e.g., variations in initial velocity depending on mission configuration and fluctuations in the state of the atmosphere according to the Martian season), the qualification of aerocapture systems would undoubtedly require several tests at scale one. 
Consequently, if, as assumed in the introduction, aerocapture is necessary for the efficiency of the mission and budget and schedule constraints are key issues, several important principles need to be applied:

- Avoid huge vehicles.

- Avoid complex shapes (e.g., avoid modules protruding on one side).

These recommendations have been taken into account in the following sections.

\subsection{Entry, descent, and landing}

The EDL (entry, descent and landing) phase is very challenging. While a number of robots have landed successfully on Mars, new technologies will have to be developed for larger, heavier vehicles $[5,18,22,24]$. A previous study demonstrated that, above a certain mass threshold, it was not possible to apply the techniques used by NASA for their robot landers [12]. The heat shield diameter would be too small for efficient braking and it may not be possible to use parachutes. Several innovative concepts have been proposed to overcome these difficulties. A heat shield may be rigid and deployable or flexible and inflatable $[5,25]$. Another idea is to provide more lift using the longest side of the vehicle or a wing shape [4]. All these concepts are technically founded. However, if heavy vehicles with very large heat shields are used, several technical studies have highlighted a significant increase in complexity, not only in the first phase of the descent but also during removal of the heat shield, the propulsive phase, and the final landing on the surface (for instance: "As the payload mass increases from 20 to 40 t, the technology challenges increase drastically." [22, page 20]. Furthermore, since a split strategy is generally preferred (e.g., the Mars ascent vehicle will precede the manned vehicle to the planet's surface), accurate guidance capabilities are required to land the modules very close to each other [26]. For all these reasons, the most difficult, uncertain, and, possibly, the most expensive part of the Mars program is likely to be developing EDL systems appropriate for a manned mission. A reasonable recommendation is, therefore, to examine the parameters of the EDL phase and investigate ways to reduce the overall complexity [19]. One critical parameter is entry velocity. Direct entry is possible, but the high velocity and large heat shield required represent significant mass penalties. An entry from orbit is therefore preferable. As aerocapture has been decided for Mars orbit insertion, entry from orbit is the logical next step. The mass of the landing vehicles is another important parameter [18,20,27]. Indeed, mass has a direct impact on the ballistic coefficient. If it is too high, atmospheric braking is inadequate and the vehicle crashes on the surface. As previously suggested, it is possible to reduce the ballistic coefficient with a larger heat shield, but at the expense of the integrated heat load and structural mass. At Mars entry, a 15-meter diameter heat shield would probably be sufficient for a 40-metric ton vehicle. If the mass is doubled, the diameter should be multiplied by the square root of 2, but this increase also has an impact on the thickness of the thermal protection system and the structural mass. One important factor, highlighted in a study by Steinfeldt et al [22], was that the fraction of the mass dedicated to EDL systems grows with the payload mass. For example, for a 20-tonne payload, EDL systems represent approximately $50 \%$ of the entry mass (also 20 -metric ton), while for a 40 -metric ton payload, they represent on the order of $60 \%$ of the entry mass (60 metric tons). The logical conclusion is that it is preferable to land the payload in several vehicles rather than a single one to save mass [19]. Another problem is that the diameter of any space structure is constrained by the diameter of the launcher. A deployable structure or LEO assembly is already required for modules above 10 meters, but complexity 
grows with diameter. For a 15-meter diameter heat shield, it is possible to deploy a rigid structure with petals stowed along the side of the vehicle [25]. Above 20 meters, the best solution is probably an inflatable structure, but deployment would be complex and the thermal and mechanical behavior of the system would be uncertain. In addition, as complexity increases, qualifying the systems for manned flight would require a long process with numerous tests at scale one in the Martian atmosphere. Obviously, these tests would be very expensive and time-consuming if the landing vehicles were huge and had to be assembled in LEO before the flight to Mars. The worst case would be to have to qualify different EDL systems for different vehicles. Finally, as in the case of aerocapture, several important principles have to be applied to reduce the complexity of EDL systems:

- The size and mass of the landing vehicles have to be reduced to the strict minimum.

- For a given payload mass, two landing vehicles sharing that payload would be lighter than a single one.

- All landing vehicles should share the same EDL systems and procedures.

\subsection{Mission architecture}

The main conclusion of the previous two sections is that the vehicles approaching Mars for aerocapture and landing should be as light and simple as possible. This may be achieved by combining the different elements in an original way. Regarding the Mars ascent vehicle and surface habitat, they may be sent separately and aerocapture may be possible. The solution adopted in the NASA reference mission for the ERV (Earth return vehicle) is not appropriate, as the vehicle would be too heavy and its shape would not be appropriate for aerocapture. The strategy proposed here is to eliminate LEO assembly by splitting the vehicle into two parts that are sent to Mars separately and dock later in Mars orbit: see Figure 2.

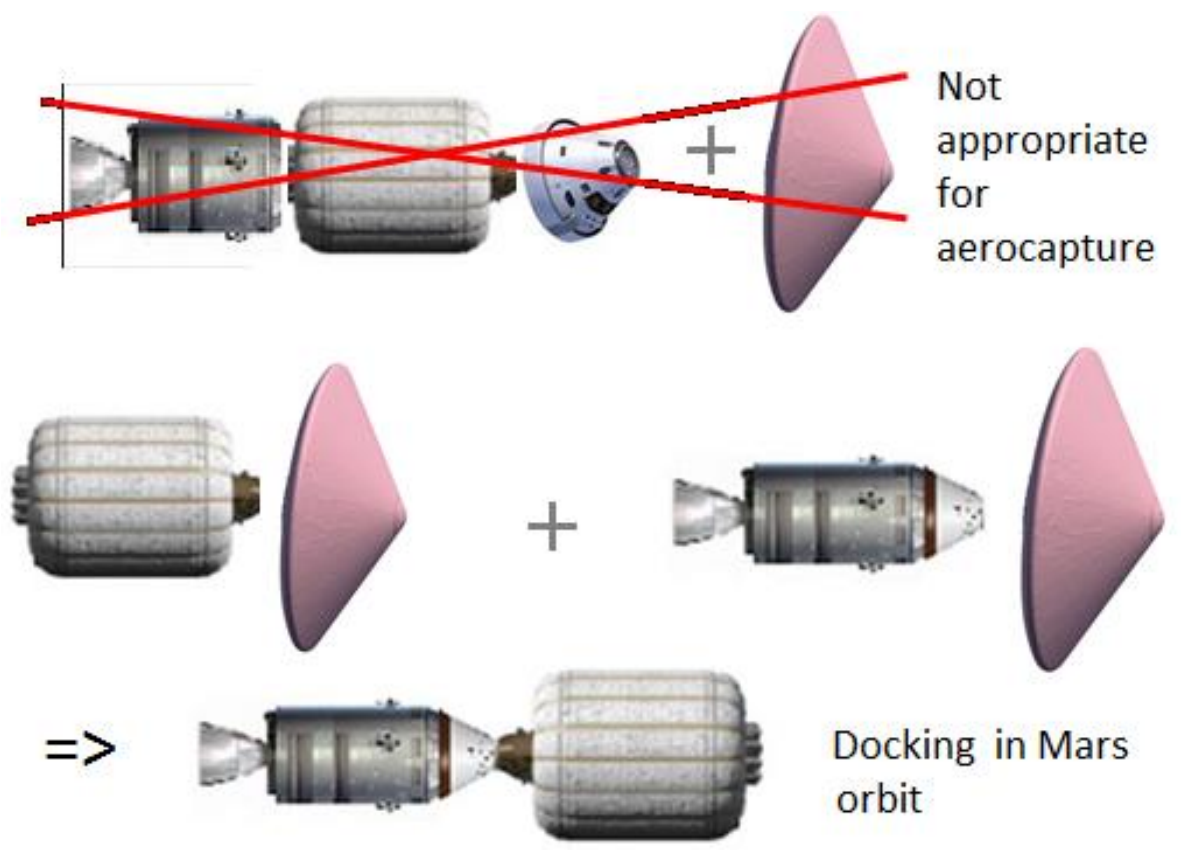

Figure 2: Preferred option for aerocapture: the ERV is split into two parts that are sent separately and dock in Mars orbit after the aerocapture maneuver. 
In our proposal, the Earth return vehicle is split into two smaller vehicles, suitable for aerocapture. In general, the deep space habitat is used for both outbound and inbound trips. However, since the astronauts have to land with the surface habitat, this option implies another docking maneuver in Mars orbit, as well as a crew transfer. This is not necessary if the crew travels to Mars in a dual-use habitat for both the outbound trip and landing on the surface. The proposed architecture is illustrated in Figure 3.



Figure 3: Proposed architecture with 4 SLS launches.

Thanks to the reduced payload for each vehicle, it is feasible to avoid LEO assembly and plan a direct flight to Mars or a simple check in LEO before the TMI burn, a few days after the launch. Some assets will be deployed on Mars before the manned vehicle launch. The current proposal is to send the Mars ascent vehicle with in situ resource utilization systems directly to Mars on the first flight. A single SLS is sufficient: see the following sections for a detailed feasibility analysis. A second SLS transports the first part of the return vehicle, the deep space habitat into Mars orbit. These two SLS launches are scheduled during the first launch window. The second launch window occurs two years later. The dual -use habitat is launched first into LEO by the $3^{\text {rd }}$ SLS. A few weeks later, the crew arrives in LEO on Orion, using the fourth SLS. The standard service module of Orion is not used in this configuration, but is replaced by the 
wet propulsion system for the return vehicle. The two modules dock in LEO and the crew is transferred to the dual use habitat. Then, the two vehicles separate and the TMI burn is triggered for each vehicle. As stated in the introduction, it is assumed that the propulsion system for the TMI burn is capable of transporting a 45-metric ton payload to Mars. After aerocapture, the second part of the return vehicle docks with the first one and the ERV moves into parking orbit. After aerocapture, provided that the MAV and ERV are ready for the return, the manned vehicle enters the Mars atmosphere and the dual-use habitat lands on the surface. The landing needs to be relatively accurate to minimize the distance to the Mars ascent vehicle: 10 kilometers is considered acceptable and achievable, as currently expected for the next robotic rovers. In case of difficulties during the descent, unpressurized rovers and inflatable structures provide long-range capabilities to ensure that the astronauts can reach the MAV. After approximately 500 days on the surface, the crew uses the MAV to return to Mars orbit and rendezvous with the return vehicle. The TMI burn takes place and, approximately 6 months later, the Orion capsule is used for reentry into the Earth's atmosphere.

One important question is whether the proposed architecture is realistic, with only 4 SLS launches. This question is addressed for each vehicle in the following sections. Backup issues are covered in the final section.

\section{Feasibility of a direct launch for the manned vehicle}

\subsection{Main issues}

Several key questions need to be addressed to determine the mass budget:

- The reduction of flight duration to 6 months has an impact on the $\Delta \mathrm{V}$, increasing the mass of the propulsion system and decreasing the payload mass. What is the exact impact?

- Part of the payload is dedicated to the aerocapture, entry, descent, and Mars landing systems. What mass does this represent?

- The mass of the habitat module depends on crew size and the duration of the autonomous stay on the surface. Given a maximum available mass for the habitat module, how many astronauts can be supported and for what duration?

The answers are given in the following sections.

\subsection{Reducing payload mass for fast transit}

In the introduction, a maximum of $\mathbf{4 5}$ metric tons was assumed for any interplanetary vehicle sent to Mars by a single SLS launch. That payload is only available if no effort is made to speed up the interplanetary flight, typically following an approximate Hohmann transfer trajectory for a 278-day trip, if Mars is at aphelion. A longer burn is required to reduce the transit time to 180 days. The following first order calculations have been made, assuming that:

- An Orion capsule (probably not the best choice, but adopted for the sake of simplicity) takes the crew into a $400 \mathrm{~km}$ circular orbit. They then transfer to the habitat module for the flight to Mars.

- A wet propulsion system, with a specific impulse of 450 seconds and a structural to propellant mass ratio of $12 \%$ is used for the TMI (trans-Mars injection) burn. 
- $\quad$ The minimum $\Delta \mathrm{V}$ to reach Mars from LEO is $3696.5 \mathrm{~m} / \mathrm{s}$ (Hohmann transfer, worst planetary configuration).

- In order to meet the 45-metric ton payload constraint for the TMI burn, the total mass on the 400-km parking orbit should not be greater than 124 metric tons. Remark: This figure is below 130 metric tons as the proposed circular LEO is more difficult to achieve than the one described in the SLS specifications.

The impact of the reduction in transit time was calculated on the basis of the above assumptions. The results are plotted in Figure 4. Shortening the outbound trip to 180 days (35\% reduction), necessitates reducing the payload (interplanetary vehicle) mass by only 3 tons.



Figure 4: Impact of trip duration on interplanetary vehicle mass. $x$-axis: number of days, $y$-axis: SLS payload mass in metric tons.

This result is well known and easy to understand. First, since the burn takes place in LEO, the remaining escape velocity is high. Second, the velocity of a body rotating in an elliptical orbit around the sun is high at perihelion and low at aphelion. If the aphelion of the vehicle's orbit is further than Mars, the low velocity part of the trajectory is eliminated. Consequently, reducing the duration of the trip by 10 to $30 \%$ has little impact on the amount of propellant needed for the burn. This strategy is only interesting for the manned interplanetary vehicle. In order to meet the 6-month transit time constraint, it is assumed in the following sections that the maximum mass of that vehicle is 42 metric tons instead of 45 .

\subsection{Mass of entry, descent, and landing systems}

A braking phase is required for Mars orbit insertion (MOI) prior to landing. In the proposed architecture, an aerocapture maneuver is the preferred option. Several systems are possible. In a recent NASA study, the best choice consisted of two IAD (Inflatable Atmospheric Decelerators) of different sizes to achieve appropriate deceleration at hyper- and supersonic speeds [5]. Importantly, the first heat shield may also be used for aerocapture. The last phase of the descent is propulsive. Propellant margins are taken into account for any lateral landing adjustment that may be necessary. According to NASA, the mass of these EDL systems (aerocapture included) represents $50 \%$ of the entry mass. The NASA study was based on an 
80-metric ton entry vehicle. According to another study, the ratio is likely to be even better for a lighter vehicle [22]. 50\% of the entry mass therefore seems an appropriate assumption.

Interestingly, other authors suggested using rigid deployable heat shields with carbon-composite thermal protection systems that may save additional mass [25]. The thermal protection system consists of ceramic matrix composite (CMC) elements, with internal insulation, mounted on a cold structure. The TPS also includes a thin ablative layer, mounted on top of the CMC panels, capable of withstanding much higher heat fluxes, for very demanding re-entries. This option provides a dual-use heat shield for both aerocapture and EDL. Rigid deployable systems may be more easily integrated in lighter vehicles, as the heat shield required is smaller in diameter and the petals are folded along the side of the vehicle. It would be challenging to design larger deployable heat shields. The EDL systems' mass ratio may, therefore, be smaller for the type of light interplanetary vehicle envisioned in this study. Even if better results are expected, for the sake of simplicity, in this study, the mass of aerocapture and EDL systems is considered to represent $50 \%$ of the total entry mass.

\subsection{Mass of the habitat}

Taking EDL systems into account, the remaining mass allocated for the habitat is 21 metric tons (50\% of 42). Is that sufficient for a habitat module that has to sustain the lives of several astronauts for hundreds of days? The 2014 NASA study included some estimates of the mass of that module according to the number of astronauts and the duration of use (NASA Design Reference Architecture, annex 2, 2014 [5, page 370]). These estimates were prepared by experts in life support systems, taking redundancy into account. Linear extrapolations were calculated for an arbitrary number of days, as presented in Figure 5.

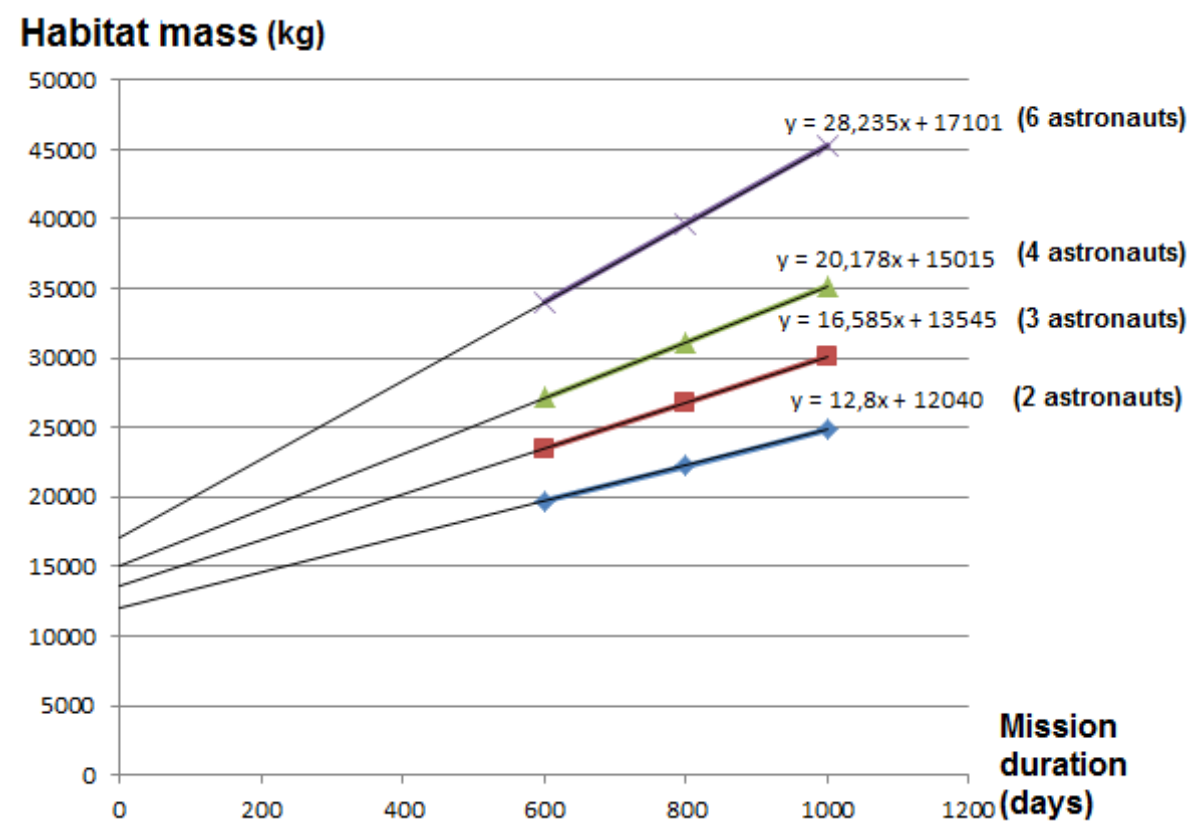

Figure 5: Mass of the habitat module depending on mission duration and crew size. Regression lines have been extrapolated from NASA data [5, page 370]. 
These estimates concern deep space. Mass estimates are probably similar for the surface of Mars. However, as suggested by NASA and in Zubrin's Mars Semi Direct scenario, it is possible to exploit local resources to provide additional consumables, especially water and oxygen $[5,15]$. It is also possible to transport consumables and spare parts on a cargo flight to Mars prior to the manned mission. It is, therefore, difficult to determine the maximum number of astronauts and trip duration according to the 21-metric tons limit. Nevertheless, the best option would be to provide enough consumables for the trip and the entire stay on the surface, representing a total of approximately 680 days.

For a crew of 4, a 21-metric ton module only provides 300 days' autonomy, which is far from optimum. With a crew of 3 , autonomy increases to 450 days, which is better but still insufficient. A crew of 3 astronauts was considered the minimum for risk mitigation and human factor issues in several studies $[1,16,27]$. As the aim was to determine the feasibility of the proposed scenario, the following assumptions were made:

- A crew of 3 is proposed for the first manned mission to Mars.

- 3 unpressurized rovers are stored in the habitat module, representing a total of $500 \mathrm{~kg}$ (the mass of an unpressurized surface vehicle is estimated by NASA at $150 \mathrm{~kg}$ [4]).

- A 20.5-metric ton habitat module provides 400 days' autonomy for the crew.

- 4.5 metric tons of consumables and spare parts, sufficient to provide a total of 680 days' autonomy, are sent to Mars on a cargo flight and pre-positioned on the surface.

- As the duration of the trip is reduced to 6 months and EDL systems bring some protection, it is assumed that there is no need to add complementary systems for radiation protection.

Consequently, the feasibility of a direct flight to Mars for the manned vehicle is not clearly demonstrated. Other vehicles are required to overcome the constraint of sending an additional 4.5metric ton payload to the surface. Back-up issues are considered in the final section of the study.

\section{Feasibility of a direct launch for the MAV}

\subsection{Main issues}

The Mars Ascent Vehicle (MAV) should be ready for takeoff on the surface of Mars prior to the launch of the manned vehicle. Unlike Mars Direct, the MAV does not return to Earth. The MAV, a small capsule, is sent to Mars orbit to join the Earth Return Vehicle (ERV). The issue is the feasibility of a direct launch for a 45-metric ton interplanetary vehicle to take the MAV to Mars. As in the previous section, it is assumed that the systems for aerocapture to achieve Mars orbit and EDL represent $50 \%$ of the mass of the interplanetary vehicle. The 2014 NASA study analyzed the MAV requirements in great detail [5]. This proposal adopts similar parameters. The ERV is parked in a $33800 \times 250 \mathrm{~km}$ orbit. The MAV is launched from Mars and docks with the ERV in that orbit. The $\Delta \mathrm{V}$ is $5625 \mathrm{~m} / \mathrm{s}$ (NASA estimate). Taking time margins into account, the life support systems of the small habitat module should be able to sustain the lives of the astronauts for a minimum of 43 hours, but the crew in this case is assumed to be 3 instead of 6.

\subsection{Mass of habitat module}

The estimates provided in the NASA study for a crew of 4 or 6 were extrapolated to a crew of 3, as presented in Table 1. Few parameters depend on the number of astronauts. All in all, reducing from 4 to 
3 astronauts reduced mass by $8.4 \%$ for the descent and $11 \%$ for the ascent. Downsizing from 6 to 3 astronauts gave a $34 \%$ reduction.

Table 1: Mass estimates for the MAV habitat module (extrapolations from NASA study [5, page 263]).

\begin{tabular}{|l|r|r|r|r|}
\cline { 2 - 5 } \multicolumn{1}{c|}{} & \multicolumn{2}{c|}{$\begin{array}{c}\text { 4 astronauts } \\
\text { (NASA data) }\end{array}$} & \multicolumn{2}{c|}{$\begin{array}{c}\text { extrapolation to 3 } \\
\text { astronauts }\end{array}$} \\
\cline { 2 - 5 } \multicolumn{1}{c|}{} & Descent & \multicolumn{1}{c|}{ Ascent } & Descent & \multicolumn{1}{c|}{ Ascent } \\
\hline Command and data handling & 204 & 204 & 204 & 204 \\
\hline GNC & 57 & 57 & 57 & 57 \\
\hline Communication and tracking & 62 & 62 & 62 & 62 \\
\hline Power & 221 & 221 & 200 & 200 \\
\hline Thermal & 139 & 139 & 110 & 110 \\
\hline ECLS & 280 & 280 & 280 & 280 \\
\hline EVA & 32 & 87 & 32 & 87 \\
\hline Structures & 778 & 778 & 720 & 720 \\
\hline Human factors & 36 & 50 & 30 & 42 \\
\hline Total dry mass & $\mathbf{1 8 0 9}$ & $\mathbf{1 8 7 8}$ & $\mathbf{1 6 9 5}$ & $\mathbf{1 7 6 2}$ \\
\hline Crew and worn equipment & 0 & 506 & 0 & 380 \\
\hline Cargo & 250 & 250 & 200 & 200 \\
\hline Non propellant fluids & 41 & 41 & 41 & 41 \\
\hline Total crew cabin & $\mathbf{2 1 0 0}$ & $\mathbf{2 6 7 5}$ & $\mathbf{1 9 3 6}$ & $\mathbf{2 3 8 3}$ \\
\hline
\end{tabular}

Table 2: Mass estimates for the MAV propulsion systems (based on NASA data [5, page 273]).

\begin{tabular}{|c|c|c|c|c|}
\hline & & \multirow{2}{*}{$\begin{array}{l}6 \text { astronauts } \\
\text { (NASA) }\end{array}$} & \multicolumn{2}{|c|}{$\begin{array}{c}\text { extrapolation for } 3 \\
\text { astronauts }\end{array}$} \\
\hline & & & $\begin{array}{l}\text { Mass for } \\
\text { ascent in kg }\end{array}$ & $\begin{array}{l}\text { Mass for } \\
\text { descent in kg }\end{array}$ \\
\hline \multirow{4}{*}{$\begin{array}{l}\text { 1st } \\
\text { stage }\end{array}$} & Inert mass & 3875 & 2557 & 2557 \\
\hline & LOX & 9627 & 6354 & 0 \\
\hline & $\mathrm{LCH} 4$ & 2917 & 1925 & 1925 \\
\hline & Total & 16418 & 10836 & 4483 \\
\hline \multirow{5}{*}{$\begin{array}{l}2^{\text {nd }} \\
\text { stage }\end{array}$} & $\begin{array}{l}\text { Inert mass (small } \\
\text { habitat included) }\end{array}$ & \multirow[t]{2}{*}{8314} & \multirow[t]{2}{*}{5487} & 4907 \\
\hline & Crew and kit & & & 0 \\
\hline & LOX & 13906 & 9178 & 0 \\
\hline & $\mathrm{LCH} 4$ & 4214 & 2181 & 2181 \\
\hline & Total & 26434 & 17446 & 7089 \\
\hline & Total & 42852 & 31712 & 11571 \\
\hline
\end{tabular}

\subsection{Mass of ascent propulsion systems}

The NASA study suggested two stages, using LO2 and LCH4 in a 3.5 ratio for a specific impulse of 369 seconds. According to the previous section, downsizing from 6 to 3 astronauts is expected to produce $34 \%$ mass savings for the habitat module. 
From Tsiolkovski's equation, all other parameters being equal, it is easy to demonstrate that a payload mass reduction of $34 \%$ implies the same percentage reduction in the propulsion system. Data for 6 astronauts and extrapolations to a crew of 3 are given in Table 2. The mass of oxygen is zero for the descent as it is expected to be produced on the surface of Mars, see next section.

\subsection{In situ resource utilization}

Several strategies have been proposed for utilizing Martian resources to produce propellant for the ascent and, possibly, consumables for the crew. Although, in the original Mars Semi-Direct concept, Zubrin and Weaver suggested that methane and oxygen could be produced from liquid hydrogen imported from Earth and carbon dioxide found in the Martian atmosphere, the NASA specialists preferred a simpler option: importing methane and producing only oxygen [5]. This resulted in increased mass, but considerably simplified the systems to be deployed on the surface, especially by avoiding the need to store hydrogen in liquid state. The same strategy is proposed here. According to the NASA study, the ISRU mass for oxygen production is less than 1 metric ton. There are several options for surface power. The preferred NASA option was a nuclear power plant. Since the oxygen production required is only 17.4 metric tons (3.5 ratio with methane), this project offers some mass savings compared to NASA estimates. The proposed total mass for ISRU and surface power is on the order of 6 metric tons.

\subsection{Launching the MAV directly from Earth}

In Section 3.3, the mass of aerocapture and EDL systems was estimated at $50 \%$ of the entry mass. The maximum mass of the interplanetary vehicle was set at 45 metric tons. Therefore, 22.5 metric tons are allocated to the payload. As the MAV has a mass of 11.5 metric tons for the descent and the ISRU systems represent 6 metric tons, this still leaves a margin within the maximum 22.5-metric ton payload of the interplanetary vehicle. This spare capacity could take the 4.5 metric tons of consumables that did not fit in the manned module: see Table 3. This strategy is possible with 3 astronauts, thanks to the significant mass savings in the MAV, propellant, and consumables. Calculations indicate that it would be too heavy with a crew of 4 . However, some margins have been built into the estimate, so, for example, if the final mass of aerocapture and EDL systems is $10 \%$ less than expected, the 4 crew option may be possible.

The conclusion is therefore that the MAV and ISRU systems can be sent to Mars by a single SLS launch, provided that the crew size is 3 , or perhaps 4 , but not more.

Table 3: Mass estimates for the descent payload.

\begin{tabular}{|l|r|}
\hline \multicolumn{1}{|c|}{ System } & Mass (kg) \\
\hline MAV stage 1 & 4483 \\
\hline $\begin{array}{l}\text { MAV stage 2 (including 2675 kg for } \\
\text { the capsule) }\end{array}$ & 7089 \\
\hline ISRU and surface power systems & 6000 \\
\hline Consumables for the crew & 4500 \\
\hline Total payload mass & $\mathbf{2 2 0 7 2}$ \\
\hline
\end{tabular}




\section{Feasibility of a direct launch for the ERV}

\subsection{Main issues}

As previously described Figure 3, the ERV is split into two parts, which are sent to Mars separately and dock in Mars orbit: see Figure 6. The complete ERV must include the following elements:

- A habitat module equipped for at least 280 days (maximum duration of the Mars-Earth trip). Some margin may, however, be required, in case the crew is sent back into orbit in advance for emergency reasons.

- A propulsion system for the TEl (trans-Earth injection) burn.

- A small atmospheric re-entry capsule for the last day of the mission (e.g., Orion).

- Aerocapture systems, including a propulsion system for orbit adjustment.

In the NASA study, the preferred parking orbit for the ERV was $250 \times 33800 \mathrm{~km}$ and the $\triangle \mathrm{V}$ for TEI was 1.5 $\mathrm{km} / \mathrm{s}$. The same values are assumed here.

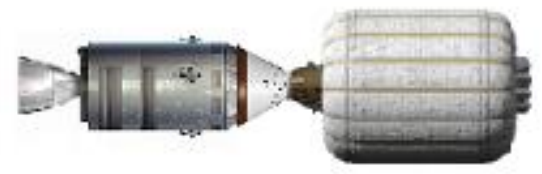

Figure 6: The ERV is composed of two modules: on the left is the wet propulsion system for the inbound trip with the Orion capsule and, on the right, the main habitat module for the return.

\subsection{Aerocapture systems}

In the NASA study, the mass of aerocapture systems represented $26 \%$ of the arrival mass (see Table 4 ), while that of a propulsion system represented over 50\% [28]. After atmospheric braking, the vehicle must leave the atmosphere and a burn has to be performed at the apoapsis of the ellipse to reach a stable Mars orbit. Propellant needs for that maneuver are rather limited. However, as it is essential to reach a specific orbit $(250 \times 33800 \mathrm{~km})$ and rendezvous with another module, some propellant margin is required. These estimates are summarized in Table 4, with extrapolations based on the NASA technical study. The initial approximation assumes that the mass of the aerocapture systems is proportional to the payload mass. This is rather pessimistic, as the Steinfeldt et al. study suggested that the fraction of the mass dedicated to aerocapture and EDL systems was generally smaller for lighter vehicles [22]. However, the proportionality principle is a good indicator for estimating the mass of these systems. Two metric tons of propellant (tank and structure included) were added for orbit adjustment and docking with the other ERV module. In order to maximize the probability of success, both ERV modules are equipped with the same orbit adjustment capabilities. 
Table 4: Mass estimates for aerocapture systems, based on NASA study [28].

\begin{tabular}{|c|c|c|c|}
\hline & System & $\begin{array}{l}\text { Dedicated } \\
\text { mass for an 80- } \\
\text { metric ton } \\
\text { vehicle (NASA } \\
\text { data) }\end{array}$ & $\begin{array}{l}\text { Dedicated } \\
\text { mass for a 45- } \\
\text { metric ton } \\
\text { vehicle on a } \\
\text { proportional } \\
\text { basis }\end{array}$ \\
\hline \multicolumn{2}{|l|}{ Avionics } & 1.9 & 1.1 \\
\hline \multirow{3}{*}{$\begin{array}{l}\text { Navigation } \\
\text { systems } \\
\text { (propulsion } \\
\text { and RCS) }\end{array}$} & Dry mass (engine, tanks, etc.) & 2.9 & 1.6 \\
\hline & Propellant for aerocapture & 4.5 & 2.5 \\
\hline & Propellant for orbit adjustment & 0 & $\begin{array}{r}2 \\
\text { (added) }\end{array}$ \\
\hline \multirow[t]{3}{*}{ HIAD } & Ablative material & 1 & 0.6 \\
\hline & Structure & 5.9 & 3.3 \\
\hline & Thermal protection systems & 4.7 & 2.6 \\
\hline \multicolumn{2}{|r|}{ Total (tonnes) } & 20.9 & 13.7 \\
\hline
\end{tabular}

\subsection{Return habitat}

The return habitat shares many features with the habitat module for the outbound trip. The mass of the habitat once again depends on the number of astronauts and flight duration, as shown in Figure 5 . In view of the available mass margin, in order to build a robust scenario, this vehicle needs to carry enough consumables for an "abort to orbit" backup option if, for any reason, it is impossible to land on Mars or stay on the surface. In this case, the return habitat should provide 772 days' life support for the crew (500 days waiting in Mars orbit, if necessary, and 272 days for the inbound trip in the worst planetary configuration). The weight of this habitat module for 3 astronauts is 26.4 metric tons. Adding aerocapture systems, the total would be around 40 metric tons, which is below the 45 -metric ton limit for the SLS payload.

\subsection{ERV propulsion stage}

The following assumptions are made in estimating its mass:

- Mars parking orbit: $250 \times 33800 \mathrm{~km}$

- $\quad \Delta V$ for a TEl maneuver: $1.5 \mathrm{~km} / \mathrm{s}$ (from NASA study [4]). Following a Hohmann transfer trajectory, it is $1.3 \mathrm{~km} / \mathrm{s}$ in the worst planetary configuration.

- $\quad$ Payload mass for TEl burn 38.3 metric tons, broken down as follows:

○ Return habitat mass: 26.4 metric tons (from Section 5.3).

- Orion capsule mass without service module: 8.9 metric tons. As recent developments suggest possible mass reductions, this is a pessimistic estimate.

$0 \quad$ Other items (RCS, docking systems, etc.): 3 metric tons

- Propellant: LCH4 and LO2, ISP=319s

- Structural to propellant mass ratio: $12 \%$ (assumed in first approximation)

According to the Tsiolkovski equation, the return propulsion stage has a mass of 19.4 metric tons. The overall mass of the fourth interplanetary vehicle that takes the ERV propulsion stage into Mars orbit 
together with the Orion capsule is around 42 metric tons. Details are provided in Table 5. The ERV propulsion stage is considered a more powerful version of the Orion service module. Interestingly, this module can be sent to Mars on a faster trajectory, close to the manned vehicle, to provide backup systems during the interplanetary flight. In conclusion to this part, it is indeed possible to send the ERV to Mars in two parts that do not exceed the 45 -metric ton limit.

See annexes 1 to 4 for the mass budget of the 4 interplanetary vehicles.

Table 5: Mass estimates for the interplanetary vehicle that takes the ERV propulsion stage and capsule to Mars orbit.

\begin{tabular}{|c|c|c|}
\hline & & $\begin{array}{l}\text { Mass } \\
\text { (tonnes) }\end{array}$ \\
\hline \multicolumn{2}{|c|}{ Orion capsule without service module } & 8.9 \\
\hline \multirow{2}{*}{$\begin{array}{l}\text { Propulsion stage } \\
\text { for return }\end{array}$} & Dry mass & 2.1 \\
\hline & Propellant & 17.3 \\
\hline \multicolumn{2}{|c|}{ Aerocapture systems (from Table 4) } & 13.7 \\
\hline \multicolumn{2}{|c|}{ Total } & 42 \\
\hline
\end{tabular}

\section{Risks, programmatic and long-term viability}

\subsection{Abort and backup issues}

A Mars mission is a risky enterprise. It is important to provide backup options at every critical stage in the mission to mitigate the risk of failure and bring the astronauts back safely. Each stage is discussed in turn:

- Oxygen production must have been completed on the surface of Mars before the crew leaves Earth and the Mars ascent vehicle must be ready for takeoff. The first part of the ERV must also have reached the Mars parking orbit before the crew launch. If the two previous conditions are not fulfilled, the mission is aborted.

- The Orion capsule for the crew launch is equipped with a standard escape system in case of abort during the first few seconds after takeoff.

- The crew must be transferred to the other interplanetary vehicle in LEO. If this maneuver fails, the crew returns to Earth in Orion.

- All systems must be checked before the two TMI burns. If there is a problem with a TMI propulsion system, the mission is aborted and the crew returns to Earth. The simplest solution is to perform another docking maneuver and transfer the crew back to Orion for Earth re-entry. A secondary backup option is to launch another Orion (or another capsule) to rescue the astronauts. 
- It is difficult to provide backup solutions to the manned vehicle during interplanetary flight. Like the Apollo missions, once the vehicle is on the trajectory to the target destination, it has to reach the vicinity of the planet before engaging any further maneuvers. However, since the second part of the ERV travels to Mars in the same TMI window, it provides interesting rescue capabilities during the trip. If, for instance, there is a problem with the life support or power systems, the Orion capsule may provide a safe haven and additional life support and power supply for a few days, while the main systems are being repaired. To ensure the feasibility of that option, it is essential to trigger the TMI burns almost simultaneously and give the same acceleration, so that the two vehicles fly close to each other.

- Aerocapture is the next maneuver, involving many systems: GNC, power, and propulsion, as well as numerous other mechanisms. If one of these systems is not functional, aerocapture has to be aborted. Several backup options have been devised to deal with the various issues.

- First backup: If the problem is detected sufficiently early, one possible option is to dock with the other interplanetary vehicle, transfer the crew to Orion, and perform aerocapture with that vehicle. One vehicle would be lost and the mission on the surface would be aborted but the crew would be safe. After aerocapture, as expected, Orion would dock with the other part of the ERV. The crew would have to wait in Mars orbit until the window opens for TEI. This is the reason why the return habitat is equipped with 772 days' life support.

- Second backup: Instead of aerocapture, the vehicle would return to Earth using a gravity assist maneuver around Mars. The best return trajectory depends on the planetary configuration. It may pass via Venus or necessitate approximately 1 year in deep space. The second interplanetary vehicle has to follow the same trajectory to prepare for the final transfer to Orion before Earth landing.

- Once the aerocapture maneuver has been initiated, it is difficult to abort. The vehicle must follow a specific corridor to exit safely. There is no backup option during that phase.

- Before EDL of the manned vehicle, the two parts of the ERV must have docked and all EDL and surface systems must be functional. If not, the mission is aborted. In case of abort, the heat shield of the manned vehicle is jettisoned and the crew carries out orbital maneuvers to dock with the ERV, which then provides a safe haven until the end of the mission.

- Once the manned vehicle enters the Mars atmosphere, there is no way to abort the landing. This is a major risk of the mission. Any Earth capsule re-entering the atmosphere faces the same problem.

- If the manned vehicle lands far from the MAV, there are several options. In case of emergency, the crew uses the unpressurized rovers and, possibly, a light inflatable habitat to reach the MAV and proceed to takeoff. Otherwise, the crew can explore the surface for several months and travel to the MAV when mission control suggests. 
- At any time while they are on the surface, the crew may decide to use the MAV and return to Mars orbit to dock with the ERV.

- Theoretically, the MAV has been checked before landing and should be operational for takeoff at any moment. However, if the MAV is non-operational and cannot be repaired while the astronauts are on the surface, there is no immediate backup option. For this reason, it would be advisable to launch the second mission at precisely the first crew's planned departure time from Mars. A new MAV with backup consumables would, therefore, arrive on Mars approximately 8 months after the theoretical departure time from the surface. 8 months is very long but ISRU systems, survival techniques, and restriction rules should enable the crew to survive an extended stay on the surface. As backup options must be clearly defined, further studies are required to assess the feasibility of this proposal.

- If the MAV fails to reach a minimum orbit above the atmosphere, the crew is lost and there is no backup option. This is one of the most dangerous mission phases.

- If the MAV reaches a safe orbit but cannot dock with the ERV using its own systems, the ERV must be capable of maneuvering to dock with the MAV.

- The TEI burn is also a risky astronautical maneuver. The ERV must be placed on an accurate interplanetary trajectory that crosses the Earth's orbit a few months later. If it fails but escapes Mars' gravitational field, the crew is lost. If it is still in Mars orbit, a backup option exists, provided that the second mission is launched at approximately the same time. The solution is to send another propulsion system for the ERV. Since there are enough consumables for a long stay in space (772 days, provided that the crew did not return to orbit too early), the crew can wait in Mars orbit until the new propulsion system arrives (with additional consumables, if necessary) and return to Earth at the next TEI opportunity.

Other backup strategies to be considered if it is felt that the risk on the surface is too high include sending a surface habitat to Mars several years in advance. This would provide a backup habitat and, possibly, a safe haven for distant exploration.

\subsection{Roadmap}

As the manned mission was not clearly defined, previous roadmaps were approximate and not optimized with, for example, intermediate missions to the Moon or asteroids [29,30,31,32]. The proposed architecture is relatively simple in comparison with others, which usually require the development and qualification of new types of propulsion systems for the interplanetary flight and heavy, complex EDL systems, as well as long, complex assembly in Earth orbit. The simplicity of this architecture also facilitates the preparatory missions and roadmap. As described in a recent paper, only two important preparatory space missions are required before the first manned Mars mission [21]:

- Full qualification Mars sample return mission, using one SLS to send a heavy payload to the surface of Mars. This includes a robot, MAV, and ISRU systems. The objective of the mission is primarily to qualify the aerocapture and EDL systems for the manned mission, which is a critical 
step. The vehicles must be at scale 1 , using EDL systems and a payload with a mass of approximately 22 metric tons each. The second objective is to collect and return samples to Earth. At the same time, the proposed mission will improve the maturity of the SLS, test ISRU systems in the Martian environment, and provide the first experience of Mars ascent, as well as the return to Earth.

- Manned, long-duration, deep-space mission: the deep-space habitat with optimized life support systems (high recycling rates) must be tested and qualified for a long stay in space. Implementing this mission in lunar orbit would provide an interesting environment for scientific experiments (e.g., remote operation of robots on the surface of the Moon).

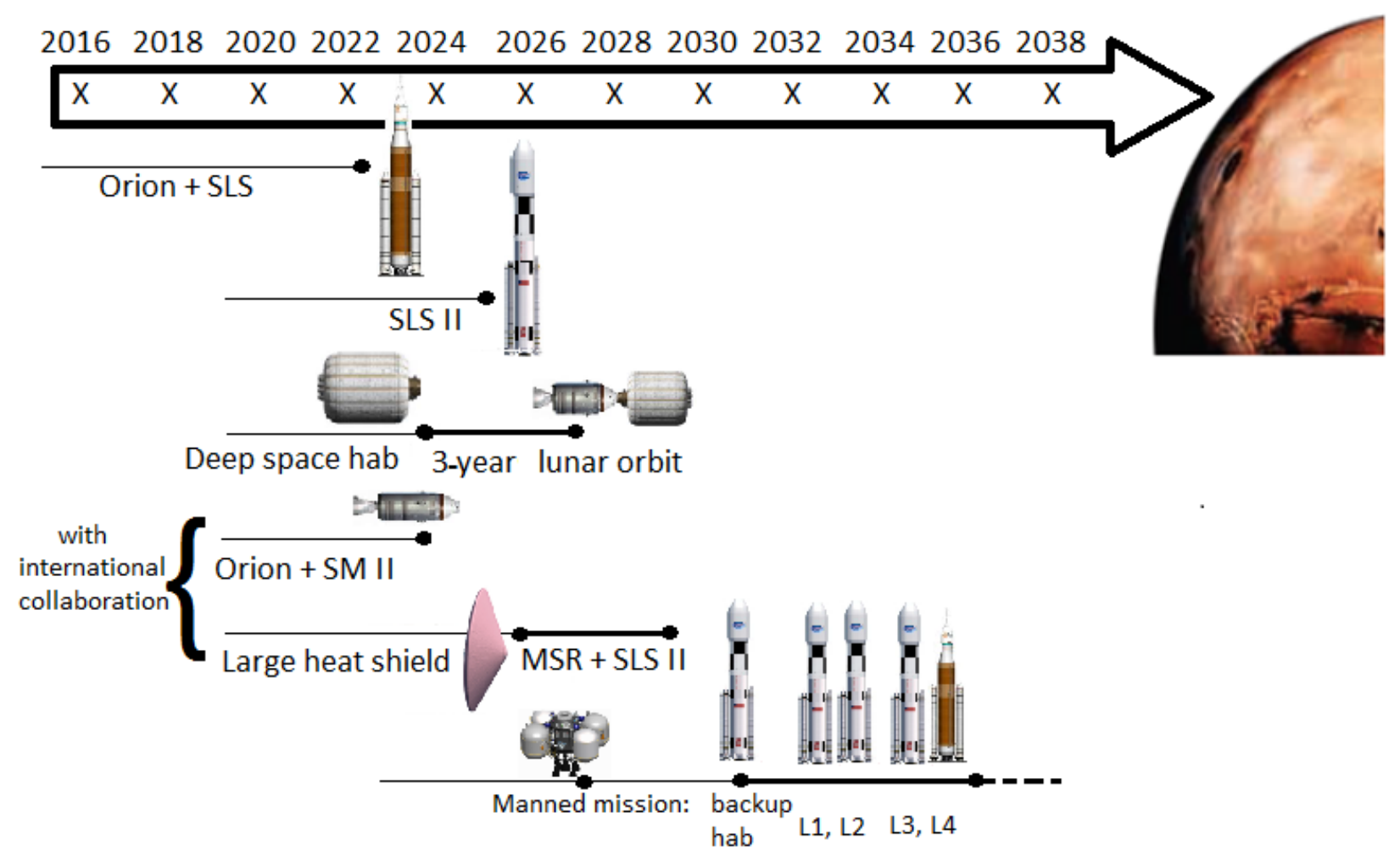

Figure 7: Roadmap for the first manned mission. Two important space missions are highlighted: Mars Sample Return with an SLS II to qualify the aerocapture and EDL systems and a 3-year manned mission in lunar orbit to qualify the deep space habitat.

These two missions and additional tests on Earth will be sufficient to qualify all systems for the Mars mission. However, even if these missions are successful, the maturity of aerocapture and EDL systems may not be sufficient for a reliable manned Mars mission. One interesting possibility is to send an unmanned habitat to the surface of Mars two years before the first SLS launch carrying the MAV. As suggested in the discussion on backup issues, an unmanned habitat provides a robust backup option, if the crew has to spend an extended period of time on the surface. At the same time, it provides a test of the EDL systems with an exact reproduction of the manned landing vehicle. Its success would 
significantly raise the probability of achieving the EDL phase with the manned vehicle. A possible roadmap for international collaboration is proposed in Figure 7.

\subsection{Comparison with electric propulsion}

Several studies suggested developing solar electric propulsion systems for the first missions to Mars [5]. These systems present disadvantages for long manned space flights but are less problematic for cargo deliveries (see NASA reference architecture [5]). The clear advantage is a high ISP with relatively simple systems and affordable technological developments. According to an initial approximation, however, missions based on both 200-400 kW solar electric systems and chemical propulsion require the same IMLEO, for 3 reasons:

- Aerocapture saves a lot of propellant. Missions based on electric propulsion do not rely on aerocapture for Mars orbit insertion, as the solar panels cannot be protected during that maneuver. In addition, a dual use heat shield is available for landing vehicles. The additional mass required in this case for aerocapture systems is very small.

- With chemical propulsion engines, the TMI burn occurs in low Earth orbit, while the solar electric burn is spread over long period of time from LEO to HEO, as well as during interplanetary transit. Gravity drag is therefore very low in the first case and much higher in the second.

- As it is necessary to minimize the time in space for the manned vehicle, the usual procedure is to send the habitat to a high Earth orbit using electric propulsion systems and then use a capsule powered by chemical propulsion to dock with it before the interplanetary burn [13]. Chemical propulsion is, therefore, still needed beyond LEO. In the 2014 NASA study, solar electric propulsion systems were also proposed for the manned vehicle, but the transit time was over 8 months, no effort was made to reduce the size of the landing vehicles, and the overall complexity of the mission was clearly one order of magnitude higher than that outlined in this proposal, based on chemical propulsion and aerocapture [5].

The above reasons explain why, in terms of IMLEO, the proposed architecture is competitive with electric propulsion-based architectures.

\subsection{Next steps}

What would be the next steps after the proposed mission? The program should definitely be continued after the first missions, for several reasons. First of all, the same architecture can be used to explore other regions of Mars. While the initial objective will essentially be scientific, future missions may be completely different, envisaging a permanent international base and tentative settlement on the surface $[4,5]$. That will require numerous one-way cargo missions. In terms of technology, it will be interesting to develop space propulsion systems that require less propellant. Interplanetary trips based on electric propulsion systems are certainly the next logical step. The same solar tugs will be suitable for transits between the low Earth orbit and Mars orbit using limited propellant. As 3 SLS launches out of 4 are linked with the MAV and return vehicle modules, sending numerous cargos to Mars will not be so difficult or expensive. If it becomes advisable to reduce the transit time for manned vehicles to less than 
6 months, chemical propulsion associated with aerocapture may still be the preferred option. As a oneway mission only requires 1 SLS launch, private enterprises may buy tickets.

After two decades, the next step may be to develop nuclear electric propulsion. However, the key parameter is the specific power of such systems. If the nuclear power plant is very heavy, this option will not be very attractive, even if the propellant needs are negligible. Nuclear power is, nevertheless, the key technology of the future, provided that high specific power values are achieved [13]. Appropriate international investments will probably be made as the number of interplanetary flights increases over time and the Martian base is developed.

\section{Conclusion}

The proposed architecture is simple, robust, and affordable. See annex 1 to 4 for detailed estimates for the 4 interplanetary vehicles. Aerocapture is the key technique that makes it feasible to use chemical propulsion systems with limited impact on the initial mass in LEO. However, aerocapture alone is not sufficient and two further options make all the difference. The first is the rendezvous in Mars orbit instead of LEO to reorganize the ERV. This strategy is fundamental to enable aerocapture and simplify the overall architecture. The second is reducing the crew to 3 astronauts. Although it restricts the human capabilities, this option greatly simplifies the architecture (no LEO assembly, only 4 SLS launches) and reduces the complexity of EDL, one of the most critical, risky phases in the mission. Interestingly, the proposed scenario is very similar to Mars Semi-Direct, published by Zubrin and Weaver in 1993 [15]. The main difference is that the ERV is sent to Mars in two parts in this configuration. Since there is no need to assemble a vehicle in LEO, the outbound trip is practically direct. The return is not direct, as the MAV docks with the ERV in Mars orbit. The proposed architecture is, therefore, a variation on the Mars SemiDirect scenario.

\section{References}

[1] L. Bessone and D. Vennemann, CDF Study Report, Human Missions to Mars, Overall Architecture Assessment, CDF-20(A), February 2004.

[2] E. Cliquet, R. Heidmann, A. Souchier, Manned Mars Missions Scenarii and Highlights on Architectures, $42^{\text {nd }}$ AIAA/ASME/SAE/ASEE Joint Propulsion Conference \& Exhibit, AIAA 2006-5126, Sacramento, California (USA), 9-12 July 2006.R.D. Braun and R.M. Manning, Mars Entry, Descent and Landing Challenges, Journal of Spacecraft and Rockets, Vol. 44 (2), 310-323, Mar-Apr, 2007.

[3] B. G. Drake, ed., Reference Mission Version 3.0 Addendum to the Human Exploration of Mars: The Reference Mission of the NASA Mars Exploration Study Team - EX13-98-036 - Exploration Office, NASA Johnson Space Center, June, 1998.

[4] G. Drake ed., Mars Architecture Steering Group, $1^{\text {st }}$ Addendum of the Human Exploration of Mars, Design Reference Architecture 5.0, NASA Johnson Space Center, 2009.

[5] G. Drake ed., Mars Architecture Steering Group, $2^{\text {nd }}$ Addendum of the Human Exploration of Mars, Design Reference Architecture 5.0, NASA Johnson Space Center, 2014. 
[6] International Academy of Astronautics, The International Exploration of Mars, 4th Cosmic Study of the IAA, April 1993.

[7] A.V. Ilin, L.D. Cassady, T.W. Glover, M.D. Carter and F.R. Chang Diaz, A Survey of Missions using VASIMR for Flexible Space Exploration, JSC report 65825, 2010.

[8] R. Myers, C. Carpenter, High Power Solar Electric Propulsion for Human Space Exploration Architectures, proc. of the $32^{\text {nd }}$ International Electric Propulsion Conference, Wiesbaden, Germany, sept. 11-15, 2011.

[9] D. Portree, Humans to Mars: Fifty Years of Mission Planning, 1950 - 2000, NASA Monographs in Aerospace History Series, no 21, February 2001.

[10] M. Raftery, D. Cooke, J. Hopkins, B. Hufenbach, An affordable mission to Mars, proceedings of the $64^{\text {th }}$ Int. Astronautical Conference, IAC-13, A5, 4-D2.8.4, Beijing (China), October 2013.

[11] J.M. Salotti, Simplified scenario for manned Mars missions, Acta Astronautica, vol. 69, 266-279, 2011.

[12] J.M. Salotti, Revised Scenario for Human Missions to Mars, Acta Astronautica, vol. 81, p. 273-287, 2012.

[13] T.D. Schmidt, W. Seboldt and M. Auweter-Kurtz, Flexible piloted Mars mission using continuous electric propulsion, Journal of Spacecraft and Rockets, vol. 43 (6), 2006.

[14] R. Zubrin and D. A. Baker, Mars Direct: Humans to the Red Planet by 1999, proceedings of the $41^{\text {st }}$ Congress of the International Astronautical Federation, 1990.

[15] R. Zubrin and D. Weaver, Practical Methods for Near-Term Piloted Mars Missions, AIAA 93-2089 AIAA/SAE 29th Joint Propulsion Conference, Monterey CA, 1993.

[16] G. Genta, J.-M. Salotti and A. Dupas, IAA Study Group 3.16: Cosmic Study on Global Human Mars System Missions Exploration. Proceedings of the $66^{\text {th }}$ International Astronautical Congress, IAC-15A5.2, Jerusalem, 12-16 October 2015.

[17] T.A. May and D.S. Creech, NASA's Space Launch System (SLS) Program: Mars Program Utilization, NASA MSC report no 20120015287, 2012.

[18] R.D. Braun and R.M. Manning, Mars Entry, Descent and Landing Challenges, Journal of Spacecraft and Rockets, Vol. 44 (2), 310-323, Mar-Apr, 2007.

[19] J.M. Salotti, New Trade Tree for Manned Mars Missions, Acta Astronautica, Volume 104, Issue 2, p. 574-581, 2014.

[20] J.M. Salotti, E. Suhir, Some Major Guiding Principles to Make Future Manned Missions to Mars Safe and Reliable, Proceedings of the IEEE Aerospace Conference, Big Sky, Montana (USA), pp. 1-6, March 2014.

[21] J.M. Salotti and R. Heidmann, Roadmap to a Human Mars Mission, Acta Astronautica, Volume 104, Issue 2, p. 558-564, 2014. 
[22] B. Steinfeldt, J. Theisinger, A. Korzun, I. Clark, M. Grant, and R. Braun, High Mass Mars Entry, Descent, and Landing, Architecture Assessment, Proc. of the AIAA Space 2009 Conference and Exposition, AIAA 2009-6684, Pasadena, CA, 14-17 September 2009.

[23] E. Belbruno and F. Topputo, "Earth-Mars Transfers With Ballistic Capture", Celestial Mechanics and Dynamical Astronomy, pp329-346, 2015.

[24] J. Cruz, A. Cianciolo, R. Powell, L. Simonsen, R. Tolson. Entry, descent, and landing technology concept trade study for increasing payload mass to the surface of Mars. $4^{\text {th }}$ International Symposium on Atmospheric Reentry Vehicles and Systems, Arcachon, France, 2005.

[25] T. Pichon, M. Lacoste, and R. Barreteau and T.E. Glass, Integrated Thermal Protection Systems and Heat Resistant Structures, proceedings of the IAC, IAC-06-D2.5.09, Valencia (Spain), 2006.

[26] A.A. Wolf, C. Graves, R. Powell, W. Johnson, Systems for pinpoint landing at Mars, Proceedings of the $14^{\text {th }}$ AIAA/AAS Space Flight Mechanics Meeting, Maui, Hawaii, February 8-12, 2004.

[27] J.M. Salotti, R. Heidmann and E. Suhir, Crew Size Impact on the Design, Risks and Cost of a Human Mission to Mars, Proceedings of the IEEE Aerospace Conference, Big Sky, Montana (USA), pp. 1-9, March 2014.

[28] A.M. Dwyer-Cianciolo, et al., "Entry, Descent and Landing Systems Analysis Study: Phase 1 Report," NASA-TM-2010-216720, July 2010.

[29] B. Hufenbach, K. C. Laurini, J.-C. Piedboeuf, B. Schade, K. Matsumoto, F. Spiero, A. Lorenzoni, The Global Exploration Roadmap, proceedings of the 62nd Int. Astr. Congress, IAC-11.B3.1.8, Cape Town, October 2011.

[30] International Space Exploration Coordinating Group, The Global Exploration Roadmap, ISECG Technical Report, August 2013.

[31] M. A. Viscio, E. Gargioli, J. A. Hoffman, P. Maggiore, A. Messidoro, N. Viola, A methodology to support strategic decisions in future human space exploration: from scenario definition to building blocks assessment, Acta Astronautica, 91, pp. 198-217, 2013.

[32] K. Ho, O. L. deWeck, J, A.Hoffman, R. Shishko, Campaign-level dynamic network modelling for spaceflight logistics for the flexible path concept, Acta Astronautica, vol.123, pp.51-61, 2016. 
ANNEX 1: Mass of $1^{\text {st }}$ interplanetary vehicle

\begin{tabular}{|c|c|c|c|}
\hline & \multirow{2}{*}{$\begin{array}{r}\text { Mass in kg } \\
2557\end{array}$} \\
\hline \multirow{9}{*}{ (Credit NASA) } & \multirow{4}{*}{$1^{\text {st }}$ stage } & Inert mass & \\
\hline & & Propellant: LOX & 0 \\
\hline & & Propellant: LCH4 & 1925 \\
\hline & & Total & 4483 \\
\hline & $2^{\text {nd }}$ stage & $\begin{array}{l}\text { Inert mass } \\
\text { (including habitat } \\
\text { module) }\end{array}$ & 4907 \\
\hline & & Propellant: LOX & 0 \\
\hline & & Propellant: LCH4 & 2181 \\
\hline & & Total & 7089 \\
\hline & & otal MAV & 11571 \\
\hline \multirow{4}{*}{$\begin{array}{l}\text { ISRU systems + } \\
\text { additional LSS }\end{array}$} & \multicolumn{2}{|c|}{ ISRU systems } & 945 \\
\hline & \multicolumn{2}{|c|}{ Surface power systems } & 5000 \\
\hline & \multicolumn{2}{|l|}{ Others } & 500 \\
\hline & \multicolumn{2}{|c|}{ Additional LSS } & 4300 \\
\hline \multicolumn{3}{|c|}{ TOTAL payload mass } & 22317 \\
\hline \multirow{11}{*}{$\begin{array}{l}\text { Aerocapture and EDL } \\
\text { systems }\end{array}$} & \multicolumn{2}{|c|}{ TPS for aerocapture } & 550 \\
\hline & \multicolumn{2}{|c|}{ Avionics and separation structure } & 1050 \\
\hline & \multicolumn{2}{|c|}{$\begin{array}{l}\text { Propulsion for descent control, } \\
\text { RCS dry mass }\end{array}$} & 1610 \\
\hline & \multicolumn{2}{|c|}{$\begin{array}{l}\text { Propulsion for descent control, } \\
\text { RCS propellant }\end{array}$} & 2490 \\
\hline & \multirow{4}{*}{\multicolumn{2}{|c|}{$\begin{array}{l}\text { HIAD } \\
\text { structure } \\
\text { HIAD thermal } \\
\text { protection }\end{array}$}} & 3270 \\
\hline & & & 2600 \\
\hline & & & \\
\hline & & & 1160 \\
\hline & (Credit N & & \\
\hline & \multicolumn{2}{|c|}{ Descent stage, dry mass } & 5760 \\
\hline & \multicolumn{2}{|c|}{ Descent stage, propellant } & 4540 \\
\hline \multicolumn{3}{|c|}{ TOTAL EDL SYSTEMS ( $50 \%$ of total) } & 22317 \\
\hline \multicolumn{3}{|c|}{ TOTAL } & 44634 \\
\hline
\end{tabular}




\section{ANNEX 2: Mass of interplanetary vehicle that takes the return habitat to Mars orbit (ERV part 1)}

\begin{tabular}{|c|c|c|c|}
\hline & & & Mass in kg \\
\hline & \multicolumn{2}{|c|}{$\begin{array}{l}\text { Return habitat for } 3 \text { astronauts } \\
\text { with } 778 \text { days autonomy }\end{array}$} & 26350 \\
\hline \multicolumn{3}{|c|}{ TOTAL PAYLOAD MASS } & 26350 \\
\hline \multirow{7}{*}{$\begin{array}{c}\text { RCS and } \\
\text { aerocapture } \\
\text { systems }\end{array}$} & \multicolumn{2}{|c|}{ Avionics and separation structure } & 1100 \\
\hline & \multirow{3}{*}{$\begin{array}{l}\text { Propulsion } \\
\text { system for } \\
\text { trajectory } \\
\text { control (RCS) }\end{array}$} & Dry mass & 1600 \\
\hline & & $\begin{array}{ll}\begin{array}{l}\text { Propellant } \\
\text { descent control }\end{array} & \text { for } \\
\end{array}$ & 2500 \\
\hline & & $\begin{array}{l}\text { Propellant for orbit } \\
\text { adjustment }\end{array}$ & 2000 \\
\hline & \multirow[b]{3}{*}{ (Credit NASA) } & Ablative material & 600 \\
\hline & & HIAD Structure & 3300 \\
\hline & & $\begin{array}{l}\text { HIAD Thermal } \\
\text { protection system }\end{array}$ & 2600 \\
\hline \multicolumn{3}{|c|}{ TOTAL FOR RCS AND AEROCAPTURE } & 13700 \\
\hline \multicolumn{3}{|c|}{ TOTAL ERV PART 1} & 40050 \\
\hline
\end{tabular}




\section{ANNEX 3: Mass of interplanetary vehicle that brings the return propulsion system and capsule to Mars orbit (ERV, part 2)}

\begin{tabular}{|c|c|c|c|c|}
\hline & & & & Mass in kg \\
\hline \multirow{2}{*}{$=1[14$} & \multicolumn{2}{|c|}{$\begin{array}{l}\text { Wet propulsion } \\
\text { system for return }\end{array}$} & Dry mass & 2100 \\
\hline & & & Propellant & 17300 \\
\hline & \multicolumn{3}{|c|}{ Orion capsule } & 8900 \\
\hline \multicolumn{4}{|c|}{ TOTAL PAYLOAD MASS } & 28300 \\
\hline \multirow{7}{*}{$\begin{array}{c}\text { RCS and } \\
\text { aerocapture } \\
\text { systems }\end{array}$} & \multicolumn{3}{|c|}{ Avionics and separation structure } & 1100 \\
\hline & \multirow{3}{*}{$\begin{array}{l}\text { Propulsion } \\
\text { system for } \\
\text { trajectory } \\
\text { control (RCS) }\end{array}$} & \multicolumn{2}{|c|}{ Dry mass } & 1600 \\
\hline & & \multicolumn{2}{|c|}{\begin{tabular}{|ll}
$\begin{array}{l}\text { Propellant } \\
\text { descent control }\end{array}$ & for \\
\end{tabular}} & 2500 \\
\hline & & \multicolumn{2}{|c|}{$\begin{array}{l}\text { Propellant for orbit } \\
\text { adjustment }\end{array}$} & 2000 \\
\hline & \multirow{3}{*}{\multicolumn{2}{|c|}{ (Credit NASA) }} & Ablative material & 600 \\
\hline & & & HIAD Structure & 3300 \\
\hline & & & $\begin{array}{l}\text { HIAD Thermal } \\
\text { rotection system }\end{array}$ & 2600 \\
\hline \multicolumn{4}{|c|}{ TOTAL FOR RCS AND AEROCAPTURE } & 13700 \\
\hline \multicolumn{4}{|c|}{ TOTAL ERV PART 2} & 42000 \\
\hline
\end{tabular}

The ERV is assembled as illustrated below. The astronauts arrive in the MAV on the right.

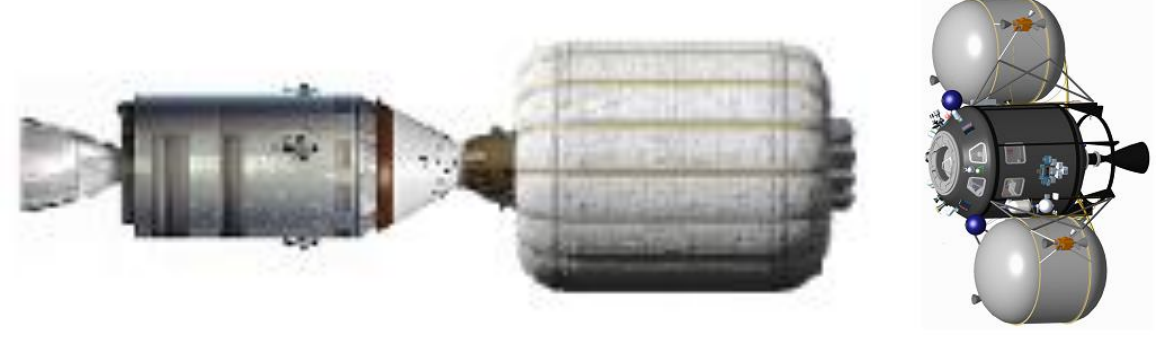


ANNEX 4: Mass of interplanetary vehicle for fast transit ( $<180$ days).

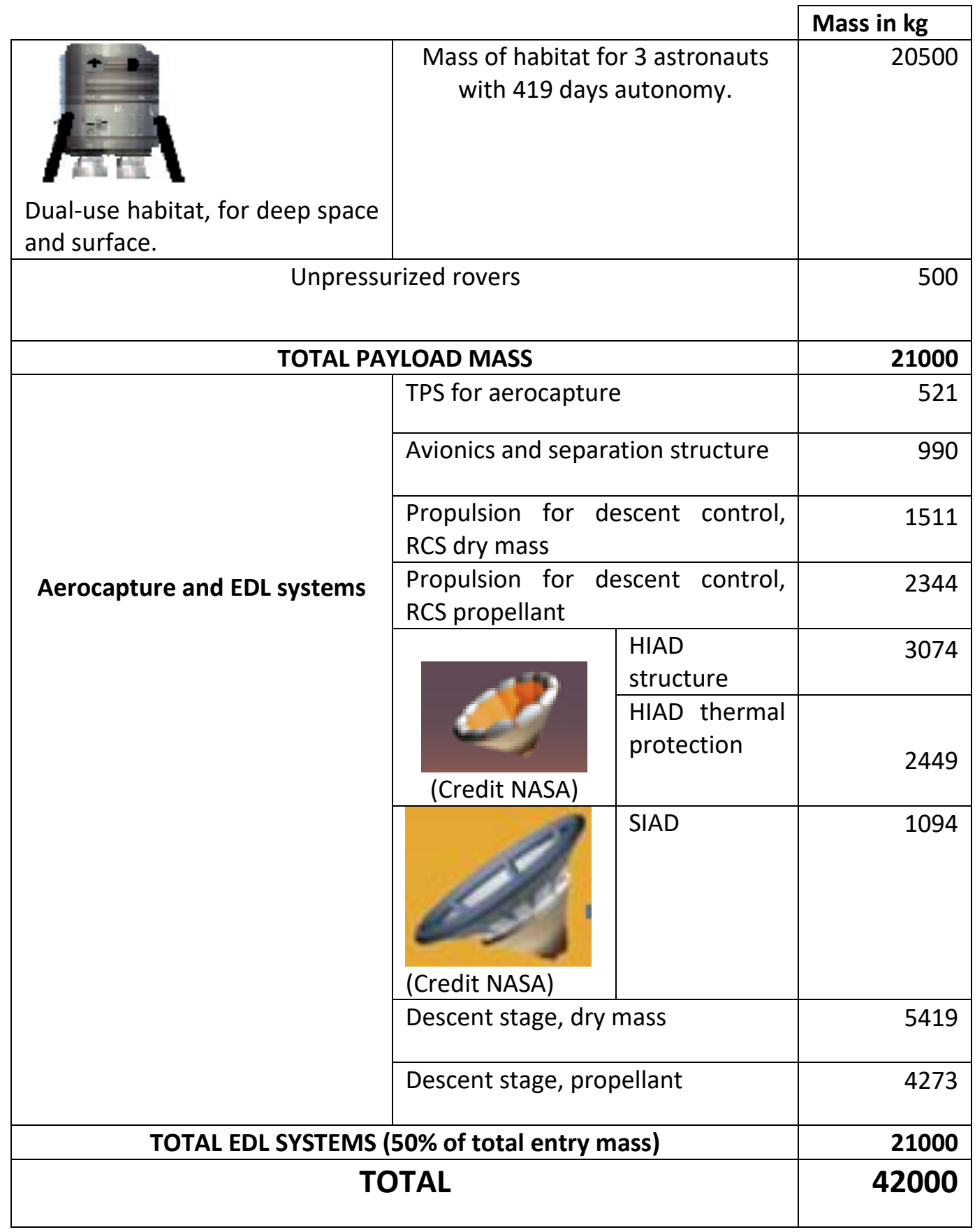

